\title{
Structure and magnetic properties of Co nanowires electrodeposited into the pores of anodic alumina membranes
}

\author{
Iwona Dobosz • Wanda Gumowska • Maciej Czapkiewicz
}

Received: 9 December 2013 / Revised: 30 May 2014 / Accepted: 23 June 2014 / Published online: 8 July 2014

(C) The Author(s) 2014. This article is published with open access at Springerlink.com

\begin{abstract}
Cobalt nanowires were obtained in the process of electrodeposition into pores of an alumina membrane. Structural research (XRD, TEM) of Co revealed the facecentered cubic structure. However, the existence of the hexagonal structure cannot be excluded due to strong texture. The influences of an external magnetic field and $\mathrm{Al}_{2} \mathrm{O}_{3}$ membrane geometry on magnetic properties of obtained wires were examined. It was found that cobalt nanowires exhibit pronounced shape anisotropy in a direction parallel to the wire axis. The highest influence on the magnetic properties is ascribed to the nanowires geometry i.e., height, diameter, and distances between single wires. Application of an external magnetic field in a perpendicular direction to the sample surface during cobalt electrodeposition increases magnetic anisotropy with a privileged direction along the wire axis. Application of the magnetic field in a parallel direction to the sample surface changes the direction of magnetization.
\end{abstract}

Keywords Anodic alumina membrane · Shape anizotropy $\cdot$ Cobalt $\cdot$ Nanowires

\section{Introduction}

Progress in miniaturization of electronic elements accompanied by a need for their higher and higher efficiency affects the development of the studies in the informatics technology.

\footnotetext{
I. Dobosz $(\bowtie) \cdot$ W. Gumowska

Faculty of Non-Ferrous Metals, AGH University of Science and

Technology, 30 Ave Mickiewicza, 30-059 Cracow, Poland

e-mail: iwona@agh.edu.pl

M. Czapkiewicz

Faculty of Computer Science, Electronics and Telecommunications, AGH University of Science and Technology, 30 Ave Mickiewicza, 30-059 Cracow, Poland
}

Nanostructural magnetic materials are used not only in informatics technologies and data storing, but also in many other areas like medicine, motorization, environment protection, sensors, and catalysis technology.

Nanowires are applied in production of magnetic information carriers $[1,2]$, biomedical materials, sound sensors and gas detectors [3-5], as well as diodes and transistors in electronics [6].

Porous and ordered alumina layer turns out to be useful as a template to build in various metals or alloys [7-10]. Metals with magnetic properties like $\mathrm{Fe}, \mathrm{Co}, \mathrm{Ni}$, and their alloys can be built into anodic alumina pores in the process of cathodic deposition from solutions of appropriate composition. Cobalt is one of the most interesting metals which belong to the group of ferromagnetic materials. It is known that metallic cobalt occurs in two crystallographic structures: hexagonal closed packed (hcp; $\alpha-\mathrm{Co}$ ) and face centered cubic (fcc; $\beta-\mathrm{Co}$ ). This strongly influences the magnetic properties of nanowires [11-13]. Moreover, it was found that the structure of cobalt wires can be affected by external magnetic field which in turn gives a possibility to control its magnetic properties.

Magnetic properties of nanowires can be controlled by: (i) appropriate selection of $\mathrm{Al}_{2} \mathrm{O}_{3}$ membrane parameters (oxide layer thickness, diameter of pores, and distance between them), (ii) optimal conditions of the electrolysis processes (current density, potential, $\mathrm{pH}$, etc.), and (iii) application of an external magnetic field during metal electrodeposition.

The influence of an external magnetic field on the electrochemical deposition of metals such as $\mathrm{Co}, \mathrm{Fe}, \mathrm{Ni}$, and its alloys on a flat electrode was mainly investigated [14-24]. So far, limited studies have been done to examine the influence of the magnetic field applied during cobalt deposition into $\mathrm{Al}_{2} \mathrm{O}_{3}$ pores on the magnetic properties of the cobalt nanowires, and previous studies had not provided clear results [25-27].

Electrodeposition under a magnetic field modifies the surface morphology and crystalline structure of deposits obtained 
on the flat electrode. The changes are ascribed to magnetohydrodynamic (MHD) convection induced by the Lorentz force [14]. The increase of convection inside the diffusion layer affects the rate of the ions transport which in turn alters $\mathrm{pH}$ values near the electrode surface. Such effects can influence changes of morphology and crystalline structure of the deposit $[18,19]$.

In the case of electrodes of high porosity, the effect of the MHD convection on morphology of the wires can be different. The fluid flow inside pores under an external magnetic field has not a stationary character. Such conditions can favor additional perturbations which can change origin morphology of the deposit [25, 26].

Application of an external magnetic field during metal electrodeposition can also induce the magnetocrystaline effect that additionally influences the change of the metal structure.

The objective of the present study is to analyze the influence of the magnetic field on magnetic properties of Co wires.

\section{Experimental}

The specimens were aluminum of the composition: $\mathrm{Al}$, min. $99.999 \%$; $\mathrm{Cu}, 0.3$ ppm; Fe, 0.3 ppm; $\mathrm{Mg}, 1.2 \mathrm{ppm}$; and $\mathrm{Si}$, $0.8 \mathrm{ppm}$ (Goodfellow). The specimen's surface was $0.8 \mathrm{~cm}^{2}$ and $0.3 \mathrm{~mm}$ thickness. Before the measurements, the specimens were degreased in acetone for $3 \mathrm{~min}$, with the application of ultrasounds. Then, the samples were annealed in an argon atmosphere for $3 \mathrm{~h}$, at $500{ }^{\circ} \mathrm{C}$, to remove any residual stress and for composition homogenization. The annealed specimens were electropolished (Stuers LectroPol-5 electropolisher) in a mixture of $\mathrm{HClO}_{4}$ and $\mathrm{C}_{2} \mathrm{H}_{5} \mathrm{OH}$ solutions with the addition of butylcellulose.

Anodic oxidation of aluminum was carried out in two stages. The anodic alumina was formed at a constant voltage in various solutions: $0.3 \mathrm{M}$ sulfuric acid at $1{ }^{\circ} \mathrm{C}, 0.3 \mathrm{M}$ oxalic acid at $2{ }^{\circ} \mathrm{C}$, and $0.17 \mathrm{M}$ phosphoric acid at $1{ }^{\circ} \mathrm{C}$. The time of the first anodizing for both sulfuric and oxalic acid solutions was $24 \mathrm{~h}$, whereas for the phosphoric acid, $2 \mathrm{~h}$. After the first anodizing stage, the oxide film was removed by immersing the samples into the solution of the composition: $0.6 \mathrm{M}$ $\mathrm{H}_{3} \mathrm{PO}_{4} ; 0.2 \mathrm{M} \mathrm{CrO}_{3}$, at $80{ }^{\circ} \mathrm{C}$ for $2 \mathrm{~h}$. After removal of the oxide film, the samples were subjected to the second anodizing stage under the same conditions as during the first one. The time of the anodizing affects the thickness of the oxide films. The second anodizing process in sulfuric, oxalic, and phosphoric acids was carried out for 3, 6, and $10 \mathrm{~h}$, respectively. After the two anodizing stages, the aluminum substrate was removed in the mixture of $0.2 \mathrm{M} \mathrm{HCl}$ and $0.1 \mathrm{M} \mathrm{CuCl}_{2}$ solution, but opening the alumina pores was achieved simultaneously. The barrier layer on the sample bottom was etched in $0.86 \mathrm{M} \mathrm{H}_{3} \mathrm{PO}_{4}$ at $30{ }^{\circ} \mathrm{C}$. After removal of both the aluminum and the barrier layer, a thin gold film was sprayed onto the sample surface from the side of the open pores to make available an electric contact during the electrodeposition of nanowires. In the areas from which the aluminum substrate was removed, a film of copper was electrodeposited in potentiostatic conditions. The diagram of the electrolyzer used in the experiment and the methodology of the preparation of the membrane was described in details in the previous paper [28].

The alumina membranes of nanoporous and ordered structure with defined pore dimensions (diameter, height, distance between pores) were obtained. These were used as a template for further electrochemical incorporation of cobalt. The process was carried out using sulfate solutions containing $0.5 \mathrm{M}$ Cobalt(II) sulfate $\left(\mathrm{CoSO}_{4}\right)$ and $0.3 \mathrm{M}$ boric acid $\left(\mathrm{H}_{3} \mathrm{BO}_{3}\right)$. The $\mathrm{pH}$ value of the solution was 3 and it was controlled by addition of sulfuric acid or sodium hydroxide. All experiments were carried out at room temperature in the three-electrode system, where a saturated calomel electrode as a reference electrode was used (SCE, $0.241 \mathrm{~V}$ vs. standard hydrogen electrode (SHE)). All potentials were recorded versus the SCE electrode, and then converted and presented with reference to the SHE. A platinum plate was used as the counter electrode. The area of the working electrode was $0.785 \mathrm{~cm}^{2}$. The experiment was carried out with "Autolab" PGSTAT30 potentiostat. Mass changes were registered by the electrochemical quartz crystal microbalance (UELKO Type M106) connected with the Autolab PGSTAT30 potentiostat. The potential was selected on the basis of the cyclic voltammetry experiments, and it was $-1.0 \mathrm{~V}$ (vs. SHE) [17].

During the cathodic deposition of Co nanowires in the presence of the magnetic field, the HV7 Walker Scientific electromagnet was used. The experiment was conducted in a homogenous external magnetic field of the strength $0.7 \mathrm{~T}$ parallel and perpendicular to the electrode surface. The morphology of the oxide films and their cross-sections were observed with the use of the high resolution scanning microscopy technique with the field emission. The scanning microscope (HITACHI S-4700 $)$ was equipped with an EDS system for the chemical composition analysis (NORAN VANTAGE). Structural studies were carried out with the use of the X-ray diffractometer (BRUKER AXS "Discover 8") and filtered $\mathrm{Cu}_{\mathrm{K} \alpha}$ radiation as well as transmission electron microscope (TEM). The magnetic hysteresis loop and its parameters (coercivity, saturation field, saturation magnetization, and the remanence) were determined by means of the Resonance Vibrating Sample Magnetometer (R-VSM) in the magnetic field directed both perpendicular and parallel to the wire axis.

\section{Results}

The electrodeposiotion of Co nanowires into the pores of $\mathrm{Al}_{2} \mathrm{O}_{3}$ membrane was carried out at the constant potential. 
The potential was selected on the basis of the cycling voltammetry experiments (three cycles). These measurements were performed on a gold electrode using solution containing $0.5 \mathrm{M} \mathrm{CoSO}_{4}, 0.3 \mathrm{M} \mathrm{H}_{3} \mathrm{BO}_{3}$ and $0.5 \mathrm{M} \mathrm{Na}_{2} \mathrm{SO}_{4}(\mathrm{pH}=3)$. Additionally, mass changes vs. potential were registered using electrochemical quartz crystal microbalance (EQCM). The curves were recorded from the initial potential of $0.5 \mathrm{~V}$ (vs. SHE), then commenced in the negative direction to the switch potential of $-1.0 \mathrm{~V}$ (vs. SHE). The backward scan was further continued and was completed at the potential of $0.5 \mathrm{~V}$.

Figure 1 shows the simultaneous measurement of current and mass changes vs. potential.

The results show that the cobalt deposition was preceded by hydrogen evolution on the Au electrode. The cobalt deposition starts at $-0.70 \mathrm{~V}$. The amount of the cathodic deposit increased until the electrode potential reached $-0.99 \mathrm{~V}$. Cathodic curve in the backward sweep indicates that cobalt was deposited in the potentials range from $\mathrm{E}_{2}=-0.99 \mathrm{~V}$ to $\mathrm{E}_{3}=-0.61 \mathrm{~V}$. Then again was codeposition of cobalt and hydrogen.

The slope of the $\Delta \mathrm{m}-\mathrm{E}$ curve in the potential range from $\mathrm{E}_{3}$ to $\mathrm{E}_{4}=-0.44 \mathrm{~V}$ indicates that the hydrogen evolution becomes dominant. Further course of the curve indicates that hydrogen evolution run on the cobalt surface.

A further polarization of the electrodes in the direction of the positive potentials corresponds to the anodic dissolution of

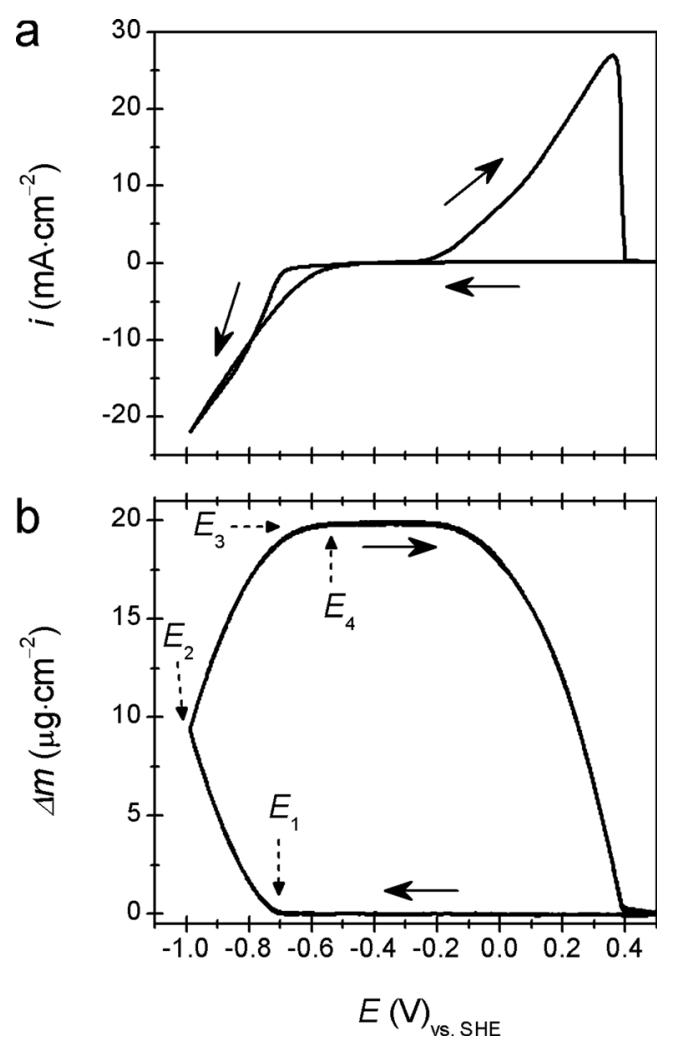

Fig. 1 Cyclic voltammograms (a) and corresponding mass changes (b) obtained for the investigated systems; $\mathrm{pH}=3$; scan speed $20 \mathrm{mVs}^{-1}$ the previously deposited metal. The anodic process was completed at $+0.4 \mathrm{~V}$ at which the mass of the deposit was equal to zero.

In this study, morphology and structure of cobalt nanowires in $\mathrm{Al}_{2} \mathrm{O}_{3}$ membrane pores were examined. Magnetic properties of the obtained materials depend on the height of the nanowires, their diameter, and distance between neighboring wires. Also, the influence of an external magnetic field applied in the electrodeposition process of Co nanowires on their magnetic properties was tested.

An influence of the electrodeposition time on the height of Co wires

Electrodeposition of Co nanowires was conducted in potentiostatic conditions at $E=-1.0 \mathrm{~V}$ (vs. SHE) using porous membrane characterized by: pore diameter $\left(D_{\mathrm{p}}=70 \mathrm{~nm}\right)$, and distance between pores $\left(D_{\mathrm{c}}=110 \mathrm{~nm}\right)$. A dependence of nanowires height and the electrolysis time was determined (Fig. 2). Results obtained in the measurements indicate that the height of cobalt wires is a linear function of time that can be described by the Eq. (1)

$L=(0.73 \pm 0.25)+(0.59 \pm 0.02) t$

where $L$ is the height of wires ( $\mu \mathrm{m}), t$ is the time (min), and correlation coefficient is 0.98 .

\section{Morphology and structure of Co nanowires}

Structural observations for received material were performed by means of scanning electron microscopy. Typical structure of $\mathrm{Co}$ wires deposited in $\mathrm{Al}_{2} \mathrm{O}_{3}$ membrane pores is shown in Fig. 3.

SEM results indicate that formation of Co wires starts in the lower part of the $\mathrm{Al}_{2} \mathrm{O}_{3}$ membrane. Nanowires deposited at a constant electrodeposition potential are built homogenously and their height depends on the process duration time.

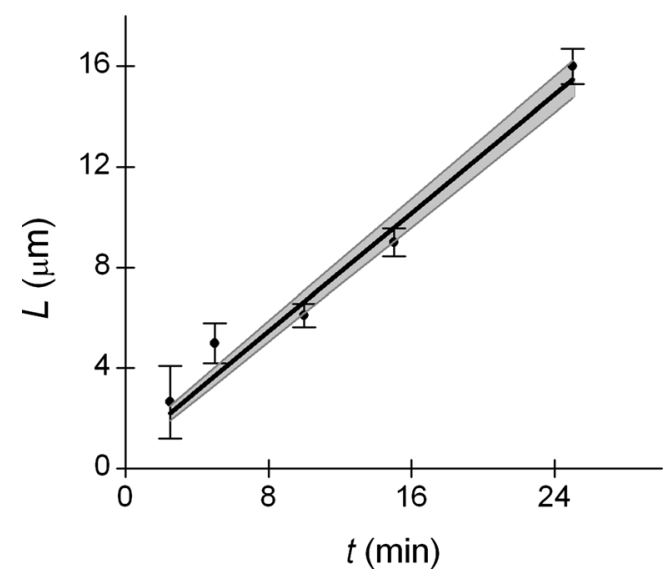

Fig. 2 Influence of the electrodeposition time on the height of the Co wires. Dimensions of the membrane pores: $D_{p}=70 \mathrm{~nm}, D_{c}=110 \mathrm{~nm}$, composition of the solution: $0.5 \mathrm{M} \mathrm{CoSO}_{4}+0.3 \mathrm{M} \mathrm{H}_{3} \mathrm{BO}_{3}$ 


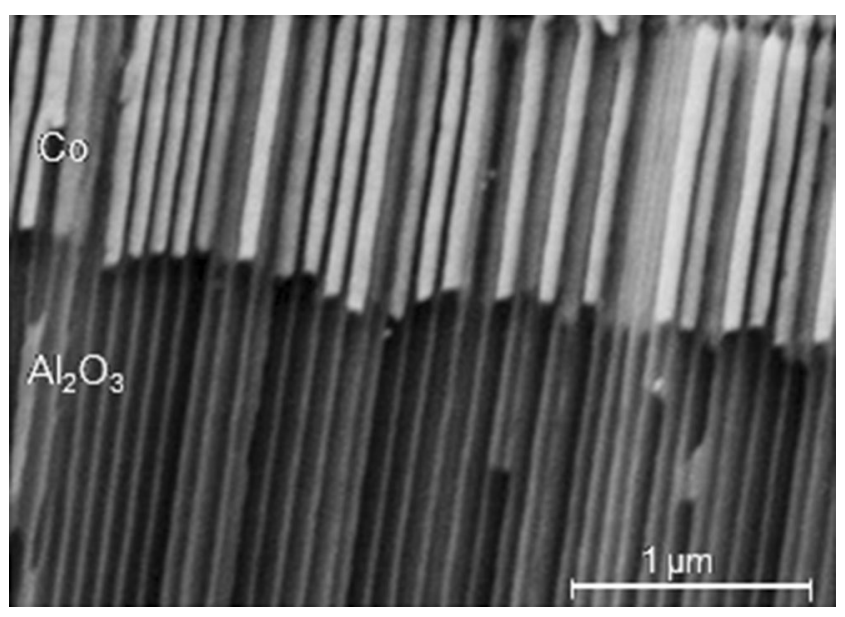

Fig. 3 A SEM micrograph of the Co wires deposited in the pores of membrane with the dimensions: $D_{p}=70 \mathrm{~nm}, D_{c}=110 \mathrm{~nm}$ in the solution: $0.5 \mathrm{M} \mathrm{CoSO}_{4}+0.3 \mathrm{M} \mathrm{H}_{3} \mathrm{BO}_{3}$ in the potential $-1.0 \mathrm{~V}$ (vs. SHE). The height of the Co wires was about $2.6 \mu \mathrm{m}$

In order to determine the structure of Co nanowires, $\mathrm{X}$-ray diffraction analysis (XRD) and transmission electron microscopy (TEM) observations were performed.

Diffractogram of Co nanowires is shown in Fig. 4. The X-ray analysis leads to the conclusion that the wires are polycrystalline. Identified (111), (220) plane reflexes at 44.2 and $75.8^{\circ}$, respectively refer to Co-fcc structure; however, the same incident angles can coincide with reflexes for the hexagonal structure (hcp) of (002), (110) planes. A weak reflex at the incidence angle of $41.8^{\circ}$ originates from the hexagonal structure. Reflexes of cobalt wires at the angle $2 \theta=44.2^{\circ}$ are less intense in comparison to the reflexes observed at the angle $2 \theta=75.8^{\circ}$. In such result, it is expected to get strong reflex derived from (101) plane at the incident angle $2 \theta=47.4^{\circ}$; however, the intensity peak is not observed on the diffractogram. It is suggested that the absence of the (101) reflex can indicate strong texture of received wires. Based on this hypothesis, reflexes coming from the hexagonal phase can be weak. Diffraction peak of Si (400) derived from the $\mathrm{Si}$ wafer substrate.

In order to obtain more detailed information on the structure of Co wires, TEM/SAD analysis was performed. An image of cross-section of the membrane structure obtained by transmission electron microscopy (TEM) is presented in Fig. 5. The size of the crystallites was about $50 \mathrm{~nm}$.

The diffraction patterns presented in Figs. $6 \mathrm{a}$, $\mathrm{b}$ were taken from the area marked (A) in Fig. 5

The SAD patterns received from the area marked in Fig. 5 correspond to Co-fcc crystallographic structure. The diffraction taken from larger area is represented by rings as it is shown in Fig. 6b. The diffraction consist of characteristics rings which can be ascribed to $\mathrm{Co}-\mathrm{fcc}$ structure. Unfortunately, based on received results, clear information on formation of Co hcp phase was not obtained.

\section{Magnetic properties of Co nanowires}

Dependencies of magnetic properties of Co nanowires on their height For Co wires of different heights, the studies of magnetic properties were conducted with the use of a resonance vibrating sample magnetometer R-VSM in a magnetic field directed perpendicularly and parallel to the wire axis. Hysteresis loops were presented as a dependency of the ratio of magnetization and magnetization saturation $\left(M / M_{\mathrm{s}}\right)$ on the magnetic field strength $(H)$.

Figure 7 shows selected curves of cobalt nanowires magnetization. In order to investigate the influence of shape geometry on the magnetic properties of Co wires, the samples for which the wire height was, respectively $6 ; 7 ; 9.4$, and $16 \mu \mathrm{m}$.
Fig. 4 X-ray phase analysis of the Co nanowires obtained in the potential $-1.0 \mathrm{~V}$ (vs. SHE). The peaks characteristic for cobalt, copper, and silicon from the substrate are described with the indices of crystallographic planes

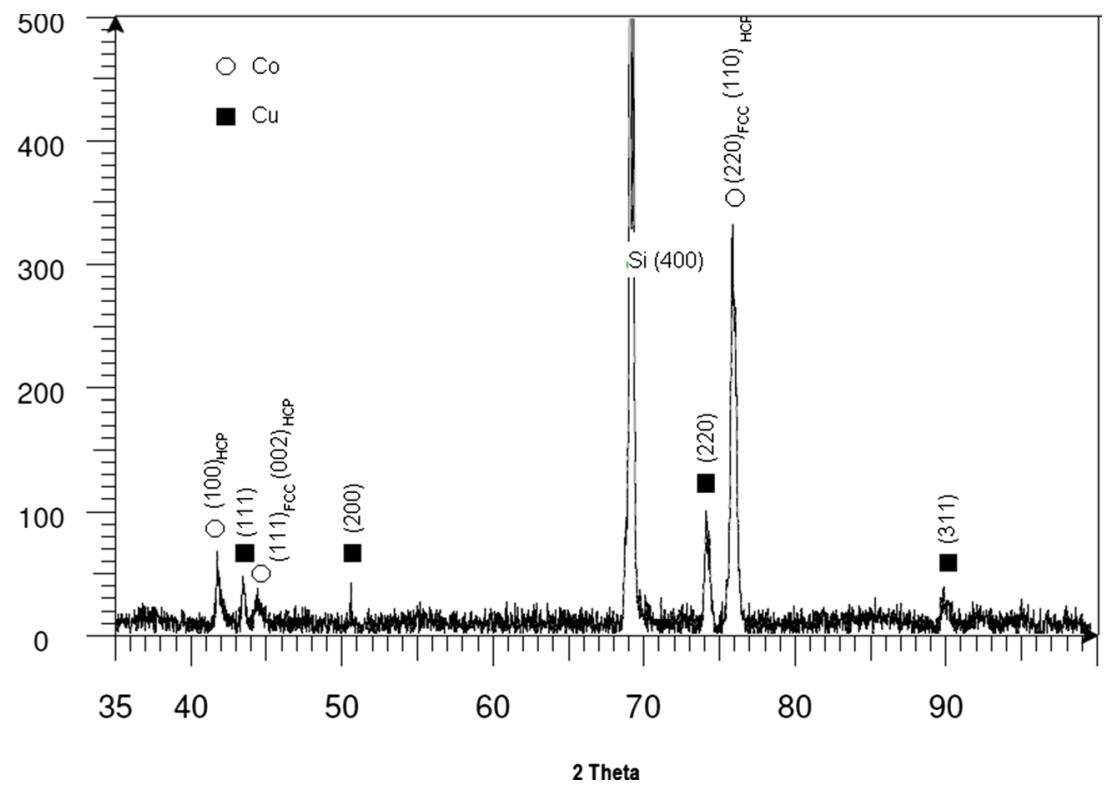




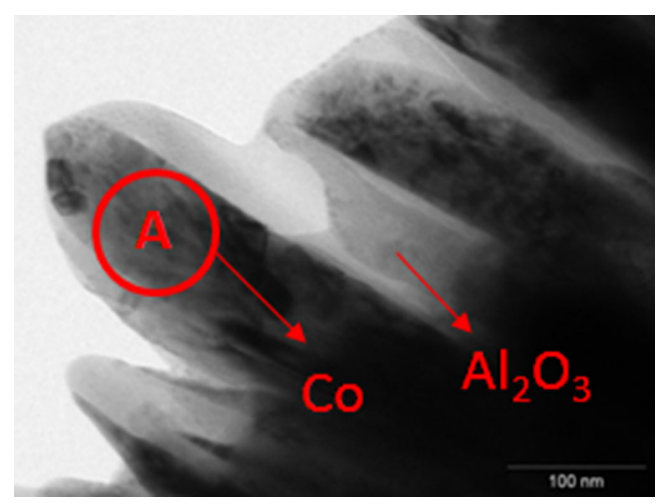

Fig. 5 A picture of the Co wires deposited in the pores of alumina membrane (Fig. 3) obtained by TEM

For a quantitative analysis of the results of magnetization dependency on the magnetic field intensity, the following values were determined or defined:

- Magnetic field strength $(H)$

- Magnetization $(M)$

- Coercive field, coercivity $\left(H_{\mathrm{c}}\right)$,

- $M_{\mathrm{r}} / M_{\mathrm{s}}$ remanence squareness, where $M_{\mathrm{r}}$ is the residual magnetization (remanence), $M_{\mathrm{s}}$ is the saturation magnetization,
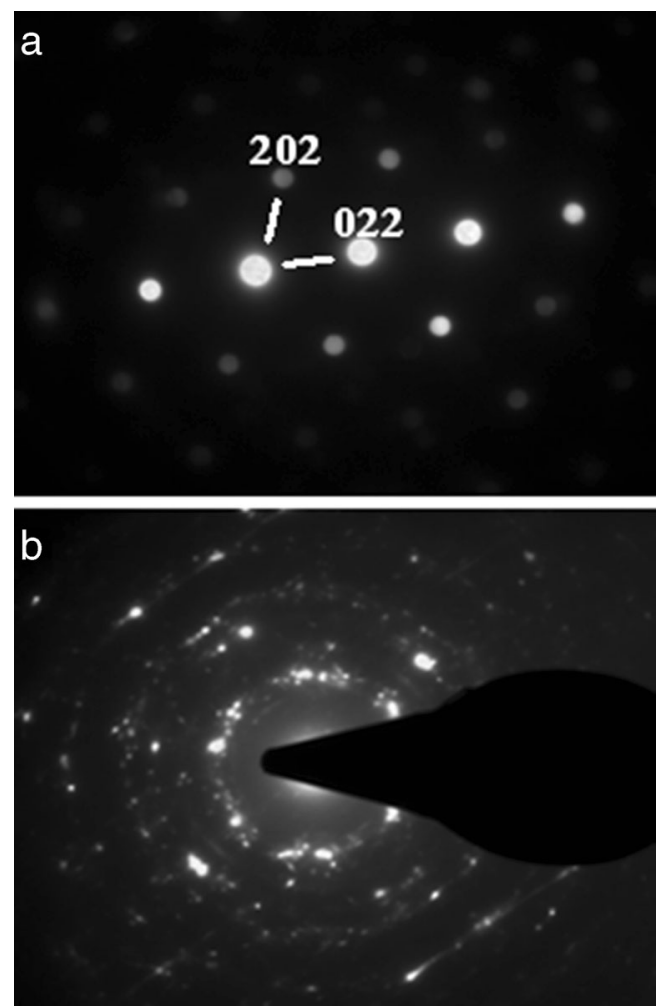

Fig. 6 The diffraction patterns taken from the area marked "A" shown in Fig. 5 a diffraction pattern corresponding to the structure cobalt from crystallographic zone $<11 \overline{1}>$ b ring pattern
- Remanent energy density $\left(\mu_{0} M_{\mathrm{r}} H_{\mathrm{c}}\right)$,

- Remanence energy $\left(\mu_{0} M_{\mathrm{r}} H_{\mathrm{c}} \cdot V\right)$, where $V$ is the nanowires volume.

The values are presented in Table 1 .

For wires of a height of $16 \mu \mathrm{m}$ (Fig. 7d), a clear magnetization anisotropy can be observed. The sample features a privileged magnetization along the wire's axis (easy direction), whereas the direction perpendicular to the wire axis is the difficult direction. This is confirmed by visible differences of remanence energy between magnetization curves. A decrease of the wire's height is accompanied by a clear decrease of anisotropy (Fig. $7 \mathrm{a}, \mathrm{b}, \mathrm{c}$ ). The highest cobalt wires $(16 \mu \mathrm{m})$ show the greatest magnetic anisotropy suitable for application of such materials in a magnetic recording.

In magnetic materials, the total anisotropy depends on coexisting and mutual competing anisotropy of the shape, magnetocrystalline anisotropy, and mutual dipolar interaction between wires. All the factors determine the final magnetization orientation. The shape anisotropy of cobalt wires depends on the wire's dimensions (diameter and height) and long wires of a small diameter prefers the magnetization direction parallel to the wire's axis. Magnetocrystalline anisotropy prefers magnetization direction along the specific crystallographic directions [29, 30].

Template of alumina membrane with embedded wires was placed on a glass substrate and diffraction analysis for that arrangement was performed. Diffraction peak of $\mathrm{Si}$ (400) shown in Fig. 4 derived from the Si wafer substrate. The diffractogram (Fig. 4) obtained for Co wires with diameter of $70 \mathrm{~nm}$ shows reflexes (111) fcc that coincide with reflexes $(002)_{\text {hcp }}$. Moreover, a weak reflex from the hexagonal structure $(100)_{\text {hcp }}$ was observed. For cobalt of the regular structure, the magnetic density of crystalline anisotropy energy $\mathrm{K}_{1}=6.3 \times 10^{4} \mathrm{~J} \mathrm{~m}^{-3}$ is lower in comparison to the density of shape anisotropy energy $\mathrm{K}_{\mathrm{s}}=\pi M_{\mathrm{s}}{ }^{2}=$ $6.0 \times 10^{5} \mathrm{~J} \mathrm{~m}^{-3}$ [25]. In case of the hexagonal structure, the density of magnetocrystalline anisotropy energy is comparable to the density of shape anisotropy energy $\left(\mathrm{K}_{1}=5.0 \times\right.$ $\left.10^{5} \mathrm{~J} \mathrm{~m}^{-3}, \mathrm{~K}_{\mathrm{s}}=\pi M_{\mathrm{s}}^{2}=6.0 \times 10^{5} \mathrm{~J} \mathrm{~m}^{-3}\right)$ [31]. For cobalt wires (diameter $70 \mathrm{~nm}$ and height $6 \mu \mathrm{m}$ ), absence of anisotropy is observed-magnetocrystalline anisotropy is as strong as shape anisotropy. Subsequently, hysteresis loops (Fig. 7a) does not show anisotropy. With the increase in height of wires (7 and $9.4 \mu \mathrm{m}$ ), shape anisotropy becomes more clear and begins to dominate, as a result, there has been a weak magnetic anisotropy along the wire axis. Further increase of the wire's height leads to a significant domination of shape anisotropy. For the longest nanowires $(16 \mu \mathrm{m})$, the energy of shape anisotropy is large enough to ensure dominance of the easy direction along the wire axis. 
Fig. 7 The hysteresis loops of the cobalt nanowires of various height obtained in the process of the electrodeposition in pores of the alumina membranes
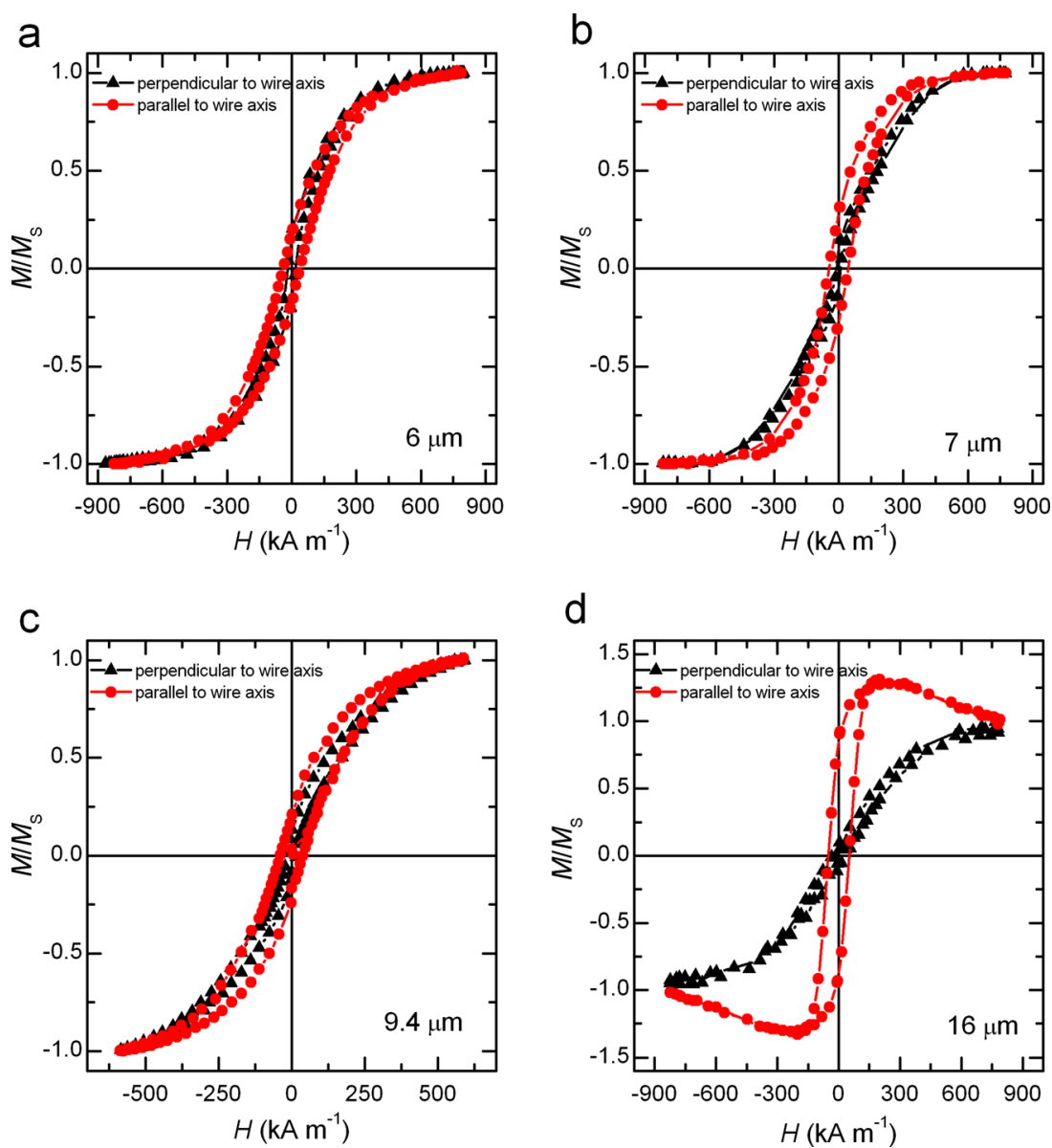

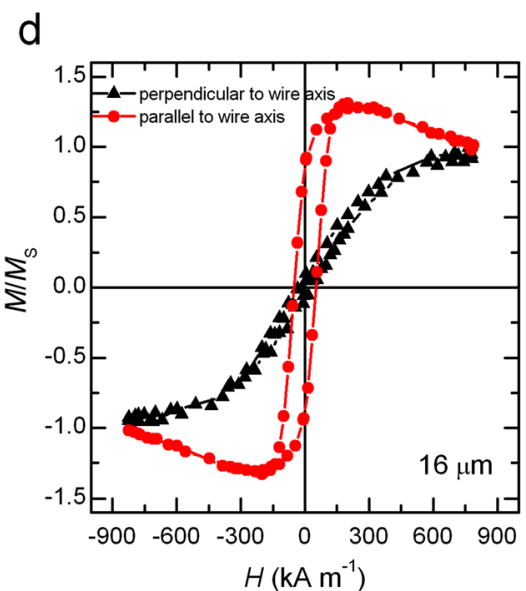

Dependencies of Co nanowires magnetic properties on wire diameter and distance between them One of the optimization methods of magnetization along the wire axis is the change of nanowires' diameter or distance between them. Electrodeposition of cobalt nanowires was carried out using membranes with the following parameters:

- $D_{\mathrm{p}}=25 \mathrm{~nm} ; D_{\mathrm{c}}=70 \mathrm{~nm} ; L=10 \mu \mathrm{m}$

- $D_{\mathrm{p}}=70 \mathrm{~nm} ; D_{\mathrm{c}}=110 \mathrm{~nm} ; L=10 \mu \mathrm{m}$

- $D_{\mathrm{p}}=200 \mathrm{~nm} ; D_{\mathrm{c}}=300 \mathrm{~nm} ; L=10 \mu \mathrm{m}$
The X-ray diffraction analysis of the structure of cobalt wires obtained in this measurement series was carried out. Figure 8 presents diffractograms obtained for samples of three pore diameters: 25,70 , and $200 \mathrm{~nm}$. Identified $\mathrm{Cu}$ peaks come from the substrate. Obtained diffractograms showed no influence of the diameter size of cobalt wires on the phase composition and crystallographic structure. The intensity of the reflexes $(220)_{\mathrm{fcc}}$ and $(110)_{\mathrm{hcp}}$ is proportional to the amount of Co due to the porosity of the oxide layer. The highest reflex at the angle $2 \theta=75.8^{\circ}$ is observed for wires of diameter

Table 1 The values characterizing the magnetic properties of the Co nanowires of different height $(L)$

\begin{tabular}{|c|c|c|c|c|c|c|c|c|c|c|}
\hline \multirow[t]{3}{*}{$L(\mu \mathrm{m})$} & \multirow{2}{*}{\multicolumn{2}{|c|}{$\begin{array}{l}\text { Remanent energy density } \mu_{0} M_{\mathrm{r}} \cdot H_{\mathrm{c}} \\
\left(\mathrm{kJ} \mathrm{m}^{-3}\right)\end{array}$}} & \multirow{2}{*}{\multicolumn{2}{|c|}{$\begin{array}{l}\text { Remanence energy } \\
\mu_{0} M_{\mathrm{r}} \cdot H_{\mathrm{c}} \cdot V \\
(\mathrm{~J})\end{array}$}} & \multirow{2}{*}{\multicolumn{2}{|c|}{$M_{\mathrm{r}} / M_{\mathrm{s}}$}} & \multirow{2}{*}{\multicolumn{2}{|c|}{$\begin{array}{l}\text { Remanence } M_{\mathrm{r}} \\
\left(\mathrm{emu} \mathrm{cm}{ }^{-3}\right)\end{array}$}} & \multirow{2}{*}{\multicolumn{2}{|c|}{$\begin{array}{l}\text { Coercivity } H_{\mathrm{c}} \\
\left(\mathrm{kA} \mathrm{m}^{-1}\right)\end{array}$}} \\
\hline & & & & & & & & & & \\
\hline & $\begin{array}{l}\text { (II) } \\
\text { To wire axis }\end{array}$ & $(\perp)$ & (II) $\times 10^{-16}$ & $(\perp) \times 10^{-16}$ & (II) & $(\perp)$ & (II) & $(\perp)$ & (II) & $(\perp)$ \\
\hline 6 & 12.2 & 5.5 & $2.84(1.7 \mathrm{keV})$ & $1.28(0.8 \mathrm{keV})$ & 0.17 & 0.16 & 241 & 222 & $40.8(510 \mathrm{Oe})$ & $20(250 \mathrm{Oe})$ \\
\hline 7 & 20.3 & 1.4 & $5.49(3 \mathrm{keV})$ & $0,38(0.2 \mathrm{keV})$ & 0.28 & 0.10 & 392 & 146 & $41.6(520 \mathrm{Oe})$ & $7.7(97 \mathrm{Oe})$ \\
\hline 9.4 & 15.0 & 3.7 & $5.42(3 \mathrm{keV})$ & $1,34(0.8 \mathrm{keV})$ & 0.20 & 0.13 & 291 & 189 & $41.2(515 \mathrm{Oe})$ & $15.6(196 \mathrm{Oe})$ \\
\hline 16 & 70.6 & 2.9 & $43.5(27 \mathrm{keV})$ & $1.81(1.1 \mathrm{keV})$ & 0.83 & 0.10 & 1,177 & 98 & $48.0(600 \mathrm{Oe})$ & $24.0(300 \mathrm{Oe})$ \\
\hline
\end{tabular}


Fig. 8 X-ray phase analysis of the cobalt nanowires with diameter of 25,70 , and $200 \mathrm{~nm}$. The peak characteristics for the cobalt and cooper from the substrate are described with the indices of crystallographic

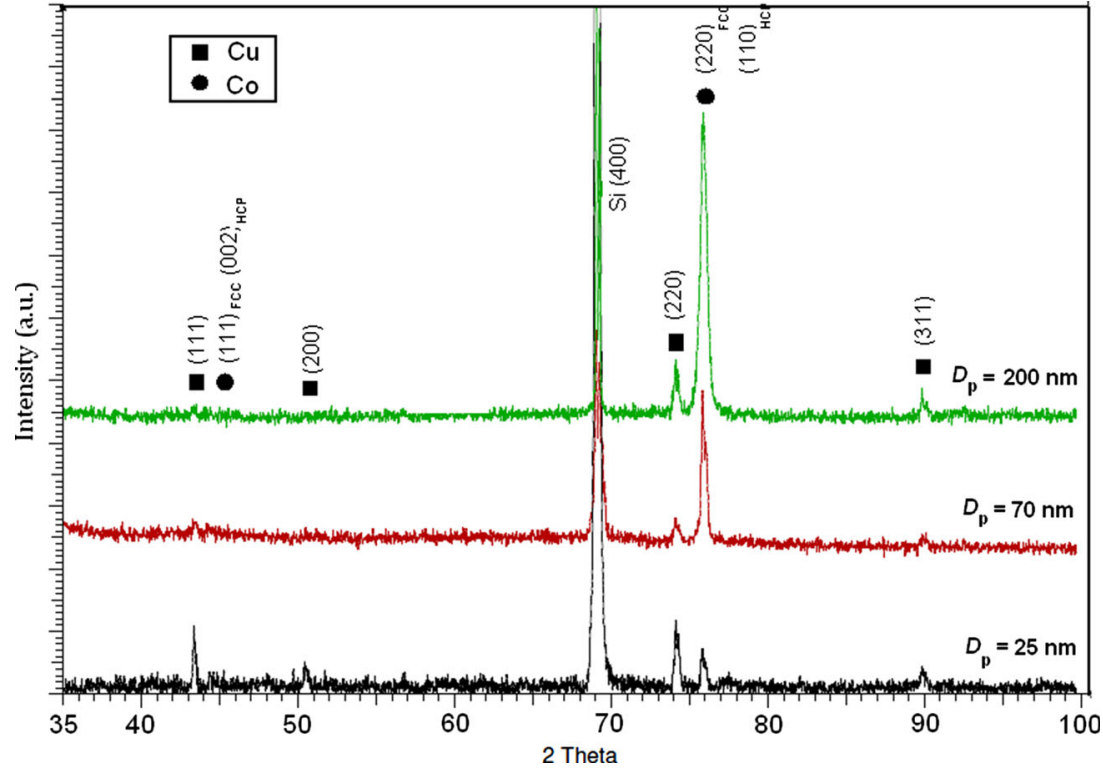

$200 \mathrm{~nm}$. Diffraction peak of Si (400) derived from the Si wafer substrate.

Magnetic properties of the obtained nanowires were determined. Hysteresis loops were presented in Fig. 9.
For wires of the smallest pore diameter, $25 \mathrm{~nm}$ (Fig. 9a), there can be observed co-existence of both easy and difficult axis of magnetization (both in the field perpendicular and parallel to the wire axis). In
Fig. 9 The hysteresis loops for the Co nanowires of the diameters: a $25 \mathrm{~nm}, \mathbf{b} 70 \mathrm{~nm}$, and c $200 \mathrm{~nm}$. The height of wires is about $10 \mu \mathrm{m}$
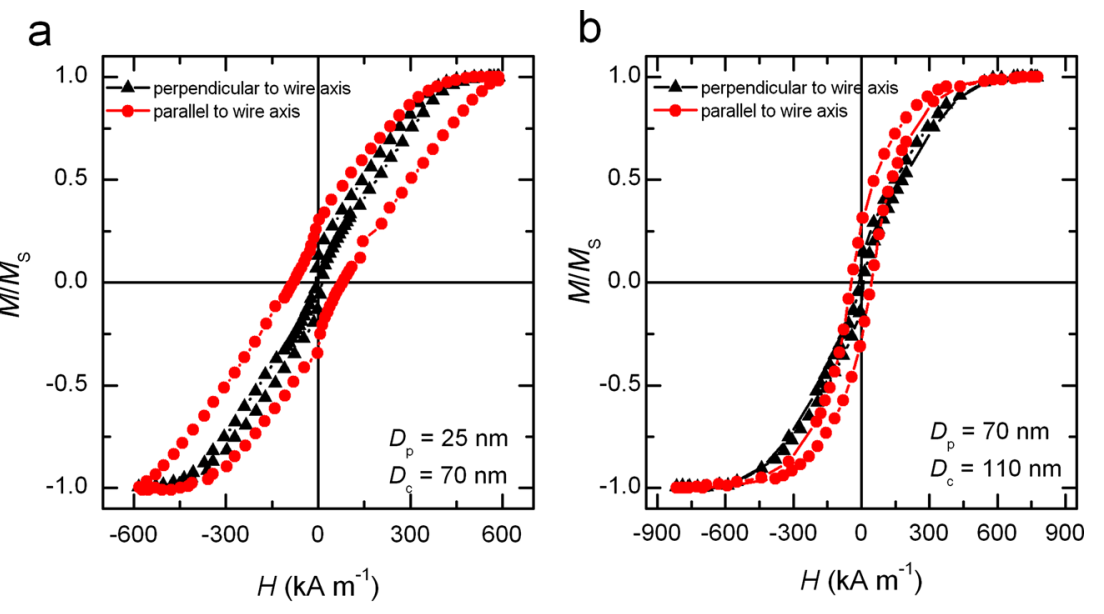

C

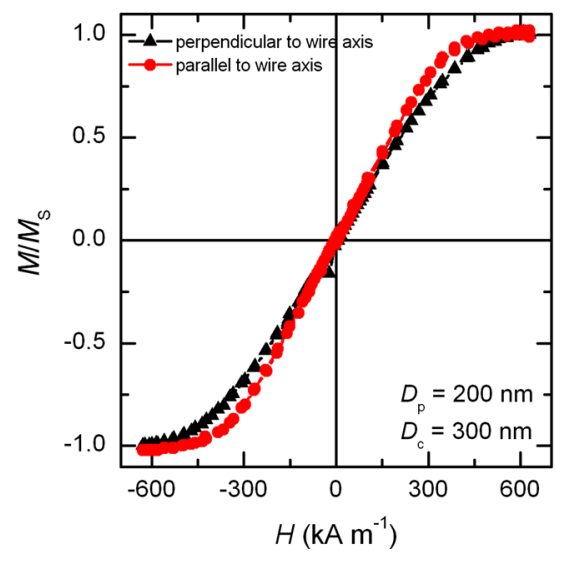


Table 2 The values characterizing the magnetic properties of the Co nanowires obtained by the electrodeposition in the alumina membrane of different parameters

\begin{tabular}{|c|c|c|c|c|c|c|c|c|c|c|}
\hline \multirow[t]{3}{*}{$D_{\mathrm{p}} ; D_{\mathrm{c}}(\mathrm{nm})$} & \multirow{2}{*}{\multicolumn{2}{|c|}{$\frac{\text { Remanent energy density } \mu_{0} M_{\mathrm{r}} \cdot H_{\mathrm{c}}}{\left(\mathrm{kJ} \mathrm{m}^{-3}\right)}$}} & \multirow{2}{*}{\multicolumn{2}{|c|}{$\begin{array}{l}\text { Remanence energy } \mu_{0} M_{\mathrm{r}} \cdot H_{\mathrm{c}} \cdot V \\
(\mathrm{~J})\end{array}$}} & \multirow{2}{*}{\multicolumn{2}{|c|}{$M_{\mathrm{r}} / M_{\mathrm{s}}$}} & \multirow{2}{*}{\multicolumn{2}{|c|}{ 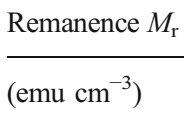 }} & \multirow{2}{*}{\multicolumn{2}{|c|}{$\frac{\text { Coercivity } H_{\mathrm{c}}}{\left(\mathrm{kA} \mathrm{m}^{-1}\right)}$}} \\
\hline & & & & & & & & & & \\
\hline & $\begin{array}{l}\text { (II) } \\
\text { To wire axis }\end{array}$ & $(\perp)$ & (II) $\times 10^{-16}$ & $(\perp) \times 10^{-16}$ & (II) & $(\perp)$ & (II) & $(\perp)$ & (II) & $(\perp)$ \\
\hline $25 ; 70$ & 43.5 & 1.9 & $2.30(1.4 \mathrm{keV})$ & $0.10(0.06 \mathrm{keV})$ & 0.3 & 0.11 & 449 & 158 & $77.4(968 \mathrm{Oe})$ & 9.8 (122 Oe $)$ \\
\hline $70 ; 110$ & 20.4 & 1.4 & $5.49(3.43 \mathrm{keV})$ & $0.38(0.24 \mathrm{keV})$ & 0.28 & 0.10 & 392 & 146 & $41.6(520 \mathrm{Oe})$ & $7.8(97 \mathrm{Oe})$ \\
\hline $200 ; 300$ & 0.11 & 0.25 & $0.34(0.22 \mathrm{keV})$ & $0.77(0.48 \mathrm{keV})$ & 0.01 & 0.02 & 18 & 28 & $4.9(61 \mathrm{Oe})$ & $7.0(88 \mathrm{Oe})$ \\
\hline
\end{tabular}

the case of the magnetic field perpendicular to the wire axis, a very small coercivity is observed.

An increase of wire diameter to $70 \mathrm{~nm}$ is accompanied by a decrease of magnetic values $H_{\mathrm{c}}, M_{\mathrm{r}}$, and $\mu_{0} M_{\mathrm{r}} H_{\mathrm{c}}$ in both directions of the magnetic field (Fig. 9). Moreover, an increase of pore diameter is accompanied by a change of anisotropy effect: the wire axis is the magnetization easy axis whereas the difficult direction is the field direction perpendicular to the wire axis. The wires are characterized by weak anisotropy along the wire axis.
An increase of the wire diameter $\left(D_{\mathrm{p}}\right)$ to $200 \mathrm{~nm}$ caused a sudden decrease in coercivity, remanence, and volume density of energy in direction parallel to the wire axis. In this case, the hysteresis is not observed in both directions of magnetization (Fig. 9c).

Table 2 shows values characterizing the magnetic field of the investigated nanowires.

The investigations indicate that the diameter of cobalt wires and distances between them significantly influence magnetic properties. An increase of pore diameter is accompanied by a decrease of coercivity, volume energy density of
Fig. 10 The hysteresis loops for the Co nanowires obtained in the solution: $0.5 \mathrm{M} \mathrm{CoSO}_{4}+0.3 \mathrm{M}$ $\mathrm{H}_{3} \mathrm{BO}_{3}$ in the potential $-1,0 \mathrm{~V}$ a in an external magnetic field $0.7 \mathrm{~T}$ perpendicular to the sample surface, $\mathbf{b}$ in an external magnetic field $0.7 \mathrm{~T}$ - parallel to the sample surface, and $\mathbf{c}$ without magnetic field
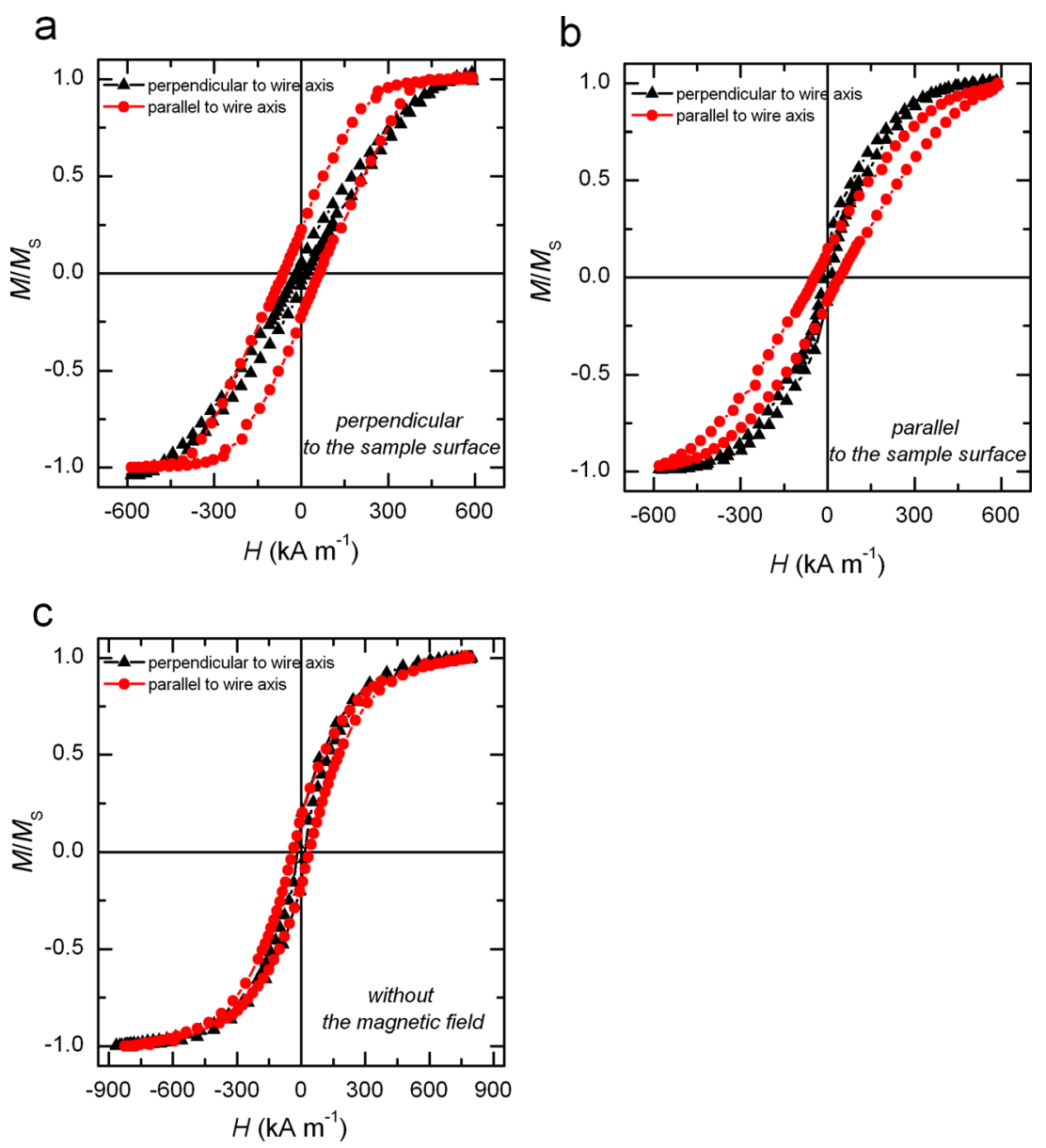
Table 3 The values characterizing the magnetic properties of Co nanowires obtained without and with the external magnetic field $(0.7 \mathrm{~T})$ in the configuration perpendicular and parallel to the membrane surface. The height of the nanowires $L=6 \mu \mathrm{m}$

\begin{tabular}{|c|c|c|c|c|c|c|c|c|c|c|}
\hline \multirow[t]{3}{*}{ Configuration } & \multirow{2}{*}{\multicolumn{2}{|c|}{$\frac{\text { Remanent energy density } \mu_{0} M_{\mathrm{r}} \cdot H_{\mathrm{c}}}{\left(\mathrm{kJ} \mathrm{m}^{-3}\right)}$}} & \multirow{2}{*}{\multicolumn{2}{|c|}{$\frac{\text { Remanence energy } \mu_{0} M_{\mathrm{r}} \cdot H_{\mathrm{c}} \cdot V}{(\mathrm{~J})}$}} & \multirow{2}{*}{\multicolumn{2}{|c|}{$M_{\mathrm{r}} / M_{\mathrm{s}}$}} & \multirow{2}{*}{\multicolumn{2}{|c|}{$\frac{\text { Remanence } M_{\mathrm{r}}}{\left(\mathrm{emu} \mathrm{cm} \mathrm{cm}^{-3}\right)}$}} & \multirow{2}{*}{\multicolumn{2}{|c|}{$\frac{\text { Coercivity } H_{\mathrm{c}}}{\left(\mathrm{kA} \mathrm{m}^{-1}\right)}$}} \\
\hline & & & & & & & & & & \\
\hline & $\begin{array}{l}\text { (II) } \\
\text { To wire axis }\end{array}$ & $(\perp)$ & (II) $\times 10^{-16}$ & $(\perp) \times 10^{-16}$ & (II) & $(\perp)$ & (II) & $(\perp)$ & (II) & $(\perp)$ \\
\hline $0 \mathrm{~T}$ & 12.3 & 5.5 & $2.84(1.8 \mathrm{keV})$ & $1.28(0.8 \mathrm{keV})$ & 0.17 & 0.16 & 241 & 222 & $40.8(510 \mathrm{Oe})$ & $20(250 \mathrm{Oe})$ \\
\hline $0.7 \mathrm{~T} \|$ & 24.2 & 1.5 & $13.4(8.4 \mathrm{keV})$ & $3.78(2.4 \mathrm{keV})$ & 0.22 & 0.05 & 311 & 68 & $62.4(781 \mathrm{Oe})$ & $17.6(220 \mathrm{Oe})$ \\
\hline $0.7 \mathrm{~T} \perp$ & 9.6 & 2.7 & $2.03(1.3 \mathrm{keV})$ & $0.62(0.4 \mathrm{keV})$ & 0.13 & 0.12 & 180 & 172 & $42.7(534 \mathrm{Oe})$ & $13.6(170 \mathrm{Oe})$ \\
\hline
\end{tabular}

remanence, and the value of the ratio $M_{\mathrm{r}} / M_{\mathrm{s}}$. On diffractograms obtained for cobalt wires of the following diameters 25, 70, and $200 \mathrm{~nm}$ at the angle $2 \theta=44.5^{\circ}$ (Fig. 8), very weak reflexes can be observed for Co coming from the regular phase that coincides with reflexes from the hexagonal phase. For wires of diameter $25 \mathrm{~nm}$ at the angle $2 \theta=44.5^{\circ}$, a slightly higher peak is observed coming from the regular phase. A greater participation of this phase is a likely cause of the increased coercive field.

An influence of the external magnetic field applied during electrodeposition on magnetic properties of the Co wires

One of the methods to carry out the guide optimization of nanowires on the privileged magnetization along the wire axis is applied to an external magnetic field during cathodic deposition of nanowires.

An external, homogeneous magnetic field $(0.7 \mathrm{~T})$ directed perpendicularly $(\perp)$ or parallel $(\|)$ to the sample surface was applied. Cobalt was deposited in $\mathrm{Al}_{2} \mathrm{O}_{3}$ membrane pores of dimensions $D_{\mathrm{p}}=70 \mathrm{~nm}$ and $D_{\mathrm{c}}=110 \mathrm{~nm}$. The magnetic properties were performed for nanowires $6 \mu \mathrm{m}$ in height. Hysteresis loops shown in Fig. 10 and in Table 3 shows the values of the magnetic field.

Cobalt wires deposited without external magnetic field (Fig. 10c) show that there is no magnetic anisotropy. There is no privileged direction of magnetization.

Application of an external magnetic field during cobalt electrodeposition in direction parallel to the wire axis (Fig. 10a) increases magnetic anisotropy: the wire axis is the easy magnetization axis whereas the field direction perpendicular to the wire axis is the difficult direction.

Application of an external magnetic field in the configuration perpendicular to the wire axis (Fig. 10b) changes the magnetization direction. Hysteresis loops obtained both in the direction of the field perpendicular and parallel to the wire axis indicate co-existence of the easy (along the wire axis) and difficult (perpendicular to the wire axis) magnetization axis. In the field perpendicular to the wire axis, small amounts of coercivity can be observed.

\section{Summary}

From among the obtained cobalt wires, the highest magnetic anisotropy suitable for application in magnetic record shows the longest $(16 \mu \mathrm{m})$ nanowires. Shorter wires (up to $9.4 \mu \mathrm{m}$ ) feature close to themselves, low remanence energy, and low ratio $M_{\mathrm{r}} / M_{\mathrm{S}}$ both in direction parallel and perpendicular to the wire axis. This indicates weak magnetic anisotropy.

For Co wires, the effective crystalline anisotropy is a result of magnetocrystalline anisotropy and shape anisotropy as well as mutual dipolar reactions between wires. X-ray diffraction analysis of cobalt wires indicates presence of the Co-fcc phase. The existence of hexagonal structure on due to present a strong texture is not precluded.

The increase in diameter of Co wires and distances between them significantly affect magnetic properties. An increase of the wire's diameter is accompanied by a decrease of coercivity, volume density of energy, and remanence.

Application of an external magnetic field during the electrodeposition process in direction perpendicular to the sample surface increases magnetic anisotropy with the privileged direction along the wire axis. By contrast, magnetic field in direction parallel to the sample surface changes the direction of magnetization.

In conclusion, magnetic properties of Co nanowires depend mainly on their height, diameter, and distance between them and these can be controlled by choice of the membrane geometry (pore diameters and distances between them) and electrodeposition time.

Acknowledgments This research work has been supported by the Polish Ministry of Science and Higher Education under project No. 10.10.180.307. The authors wish to thank Christine Damm from the Institut für Metallische Werkstoffe, IFW Dresden, Germany for the TEM investigation. 
Open Access This article is distributed under the terms of the Creative Commons Attribution License which permits any use, distribution, and reproduction in any medium, provided the original author(s) and the source are credited.

\section{References}

1. Sellmyer DJ, Zeng H, Yan M, Sun S, Liu Y (2006) Handbook of advanced magnetic materials. Springer, US

2. Sellmyer DJ, Zheng M, Skomski R (2001) J Phys Condens Matter 13:R433-R460

3. Hernández-Vélez M (2006) Thin Solid Films 495:51-63

4. McGary PD, Tan L, Zou J, Stadlera BJH (2006) J Appl Phys 99: 08B310-308B316

5. Yun M, Myung NV, Vasquez RP, Wang J, Monbouquette H (2003) Proc SPIE 5220:37-45

6. Cui Y, Lieber CM (2001) Science 291:851-853

7. Sugawara A, Streblechenko D, McCartneq M, Scheinfein MR (1998) IEEE Trans Magn 34:1081-1083

8. Routkevitch D, Tager AA, Haruyama J, Almawlawi D, Moskovits M, Xu JM (1996) IEEE Trans Electron Devices 43:1646-1658

9. Khan HR, Loebich OGR (1996) Thin Solid Films 275:207-209

10. Chaure NB, Stamenov P, Rhen FMF, Coey JMD (2005) J Magn Magn Mater 290-291:1210-1213

11. Armyanov S (2000) Electrochim Acta 45:3323-3335

12. Cavallotti PL, Vicenzo A, Bestetti M, Franz S (2003) Surf Coat Technol 169-170:76-80

13. Vicenzo A, Cavallotti PL (2004) Electrochim Acta 49:4079-4089

14. Koza JA, Mühlenhoff S, Uhlemann M, Eckert K, Gebert A, Schultz L (2009) Electrochem Commun 11:425-429
15. Krause A, Uhlemann M, Gebert A, Schultz L (2004) Electrochim Acta 49:4127-4134

16. Matsushima H, Fukunaka Y, Yasuda H, Kikuchi S (2005) ISIJ Int 45: 1001-1004

17. Dobosz I (2011) Electrochemical methods of obtaining aluminum oxide-metal (alloy) composites with magnetic properties. $\mathrm{PhD}$ thesis AGH, Krakow

18. Ispas A, Matsushima H, Plieth W, Bund A (2007) Electrochim Acta 52:2785-2795

19. Matsushima H, Ispas A, Bund A, Bozzim B (2008) J Electroanal Chem 615:191

20. Ispas A, Bund A (2011) Influence of a magnetic field on the electrodeposition of nickel and nickel-iron alloys. The 15th Riga and 6th PAMIR Conference on Fundamental and Applied MHD, Riga, Latvia, 27 June - 1 July 2005, p 135138

21. Ebadi M, Basirun WJ, Alias Y (2010) J Chem Sci 122:279285

22. Fricoteaux P, Rousse C (2008) J Electroanal Chem 612:9-14

23. Ispas A, Matsushima H, Bund A, Bozzini B (2011) J Electroanal Chem 651:197-203

24. Ispas A, Matsushima H, Bund A, Bozzini B (2009) J Electroanal Chem 626:174-182

25. Sánchez-Barriga J, Lucas M, Rivero G, Marin P, Hernando A (2007) J Magn Magn Mater 312:99-106

26. Khan HR, Petrikowski K (2002) Mater Sci Eng C 19:345-348

27. Ge S, Li C, Ma X, Li W, Xi L, Li CX (2001) J Appl Phys 90: 509-511

28. Gumowska W, Dobosz I, Uhlemann M, Koza JA (2009) Arch Met Mat 54:1119-1133

29. Kittel C (1999) Introduction to solid state physics. Wiley, New York

30. Cullity BD (1972) Introduction to magnetic materials. AddisonWesley, New York

31. Li F, Wang T, Ren L, Sun J (2004) Chin Sci Bull 49:1532-1535 